\title{
Comparison of Three Techniques to Assess Group-Level Beta and Gamma Change
}

\author{
Neal Schmitt \\ Michigan State University \\ Elaine D. Pulakos \\ Personnel Decisions Research Institute, Minneapolis
}

\author{
Amy Lieblein \\ Michigan State University
}

\begin{abstract}
Alpha, beta, and gamma change concerning student attitudes toward a college course were assessed before and after the first examination in that course for an experimental and control group. Three methodologies were used to assess change. Those proposed by Terborg, Howard, and Maxwell (1980) and Schmitt (1982) produced reasonably similar conclusions concerning change, while the methodology suggested by Zmud and Armenakis (1978) produced relatively different conclusions. The relative advantages and limitations of the procedures are discussed. The major conclusion is that much additional use and comparison of these methodologies for assessing change is necessary before researchers or practitioners can interpret the practical significance of beta and gamma change or the relative utility of various approaches to the measurement of beta and gamma change.
\end{abstract}

While the problems associated with the measurement of change have been discussed frequently (Cronbach \& Furby, 1970; Guilford, 1954; Rogosa, Brandt, \& Zimowski, 1982), Golembiewski, Billingsley, and Yeager (1976) highlighted additional measurement problems when self-report data are used to document change in organizational development, leadership, training, or job redesign efforts. The usual analysis of change involves comparing the means of "Pre" and "Post" intervention responses, and any differences between these measures are thought to occur along relatively sta-

APPLIED PSYCHOLOGICAL MEASUREMENT

Vol. 8, No. 3, Summer 1984, pp. 249-260

(C) Copyright 1984 Applied Psychological Measurement Inc.

0146-6216/841030249-12\$1.85 ble dimensions of reality. Analysis of change in this manner is designed to detect what Golembiewski et al. (1976) called alpha change.

They pointed out, however, that other types of change are possible. Specifically, Golembiewski et al. (1976) defined three types of change as follows:

"Alpha change involves a variation in the level of some existential state, given a constantly calibrated measuring instrument related to a constant conceptual domain.

Beta change involves a variation in the level of some existential state, complicated by the fact that some intervals of the measurement continuum associated with a constant conceptual domain have been recalibrated.

Gamma change involves a redefinition or reconceptualization of some domain, a major change in the perspective or frame-of-reference within which phenomena are perceived and classified in what is taken to be relevant in some slice of reality." (pp. 134-135)

Needless to say, the assessment of beta and gamma change seriously complicates efforts to evaluate change.

In their original paper, Golembiewski et al. (1976) dealt most extensively with what they termed gamma change. Using a technique outlined by Ahmavaara (1954), they factor analyzed responses to a pretest survey, factor analyzed posttest responses, and then compared the resulting structures. A very high con- 
gruence between before and after structures signaled an absence of beta and gamma change. Low congruence between before and after structureswhatever the mean differences in items-was taken as an indication of gamma and/or beta change. However, Golembiewski et al. (1976) and Golembiewski and Billingsley (1980) were not certain how beta change was identified as opposed to gamma change. In the 1980 paper, they stated "we were not then nor are we now prepared to specify what constitutes a beta change when Ahmavaara's procedure is employed"' (p. 101).

Since then three separate analytical techniques have been proposed for differentiating alpha, beta, and gamma change. First, Zmud and Armenakis (1978) proposed using the coefficient of congruence to assess the similarity between the factor structures of before and after measures. High coefficients represent a lack of gamma change, while low or negative coefficients indicate that gamma change has occurred. Alpha and beta change are differentiated using two forms of the measurement instrument in both Pre and Post intervention data collections. In addition to the usual questions that request a description of the criterion of interest, respondents are also asked to indicate "Ideal" criterion levels. By comparing Actual and Ideal scores at Times 1 and 2 and the differences between Actual and Ideal at both times, Zmud and Armenakis (1978, p. 668) identified five cases in which alpha and/or beta or no change has occurred.

Terborg, Howard, and Maxwell (1980) provided a second approach to the assessment of alpha, beta, and gamma change at both the individual and group levels of analysis. In addition to the usual Pre and Post measures, they suggested using a "Then" measure subsequent to the intervention, in which respondents are asked to indicate how they perceived themselves or the organization prior to the intervention. Differences between the Pre and Then measures are taken as evidence of a response shift or beta change. Because Then and Post ratings are taken in close temporal proximity and are likely to be from the same perspective, they are assumed to be relatively free of response shift bias. In a series of studies conducted in a variety of contexts, How- ard and his colleagues (Howard \& Dailey, 1979; Howard, Schmeck, \& Bray, 1979) have provided evidence that Pre-Then differences were indeed different from Post-Then differences, and that objective ratings of change were more similar to PostThen measurements than to Pre-Then measurements.

Schmitt (1982) developed the third method for evaluating change by adapting a technique proposed by Werts, Rock, Linn, and Jöreskog (1977) to the assessment of beta and gamma change. As outlined in Jöreskog and Sörbom (1981), the method involves the sequential testing of five hypotheses:

1. First, a test of the similarity of the Pre and Post variance-covariance matrices is conducted. If the two matrices are significantly different, it is concluded that beta and/or gamma change has occurred.

2. The second hypothesis is that the same set of common factors with similar intercorrelations exist in both Pre and Post matrices. A significant difference is interpreted as evidence of gamma change.

3. The third hypothesis, also relevant to gamma change, is that the variance-covariance matrices of the common factors are similar for the Pre and Post measures.

4. The fourth hypothesis is that the factor loadings are identical across measurement items.

5. The last hypothesis tested is that the uniquenesses associated with the measured variables are invariant across time.

While the chi-square associated with tests of these hypotheses is useful in assessing whether a particular model accounts for Pre and Post intervention matrices, of more interest in the assessment of beta and gamma change is the difference in chi-squares associated with tests of different hypotheses. Specifically, gamma change is assessed by comparing the difference between the chi-squares produced in testing Hypotheses 2 and 3, and beta change is determined by comparing the difference between the chi-squares for tests of Hypotheses 3 and 4. However, because these chi-square tests of significance are affected by the sample size, degree of fit statistics are perhaps more informative. 
Both the Zmud and Armenakis (1978) and the Terborg et al. (1980) methodologies represent useful attempts to assess beta change and to distinguish it from alpha and gamma change. However, both approaches necessitate a significant lengthening of the questionnaires to include additional (i.e., "Ideal," "Then") measures. The major advantage of the Schmitt (1982) approach is that only one Pre and Post measure is necessary to assess beta and gamma change. Further, multiple tests of significance are required in using either the $\mathrm{Zmud}$ and Armenakis or the Terborg et al. approach. This problem is probably less severe if the experimenter focuses on questions of practical significance or variance accounted for rather than on the significance levels. Indeed, this is the approach suggested by Terborg et al. (1980).

The purpose of the present paper was to compare the results of these three analytical techniques for assessing beta and gamma change. If all three produce similar results and conclusions, use of the Schmitt (1982) approach would certainly be most appropriate because the need to collect additional forms of the response measures would not exist. If the Zmud and Armenakis (1978) and the Terborg et al. (1980) approaches yield similar conclusions and they are inconsistent with those proposed by Schmitt, it would seem that a single Pre and Post measure is insufficient. If all three approaches yield different conclusions, further conceptualization and measurement of beta and gamma change should follow.

\section{Method}

\section{Sample and Procedure}

The sample consisted of 110 students in an introductory industrial/organizational psychology course. Student evaluations of the instructor were the measures of interest. After the third 1-hour class session, all respondents were asked to complete evaluations of teacher performance. The first exam, which served as the intervention, took place during the twelfth class meeting. During the class immediately prior to the examination, 61 of the 110 students were again asked to complete the teacher evaluation form. This group served as the control group. The remaining 49 students, who comprised the experimental group, responded to the teacher evaluation measures immediately after the first exam.

\section{Measures}

Students evaluated their instructor on a 16-item measure with four a priori factors labeled as follows: Instructor Involvement (Inst), Student Interest (StIn), Course Demands (CD), and Course Organization (CO). Each scale consisted of four Likert-type items, which had five response options ranging from "Superior"' (1) to "Inferior" (5).

At both administrations of the instrument, students were also asked to respond to the Ideal measure, which was preceded with the following set of instructions: "Please answer the following items indicating what the ideal levels of each item are. In other words, if this were a perfect course, how would you rate each of the items?' 'The Then measure was presented only at the second or post administration, and it was preceded by the following instruction: "Please indicate how you felt about this course during the first week of the term." Administration of the measures (Pre and Ideal at Time 1; Post, Ideal, and Then at Time 2) was counterbalanced in both conditions.

\section{Data Analyses and Results}

\section{Zmud-Armenakis Analyses}

Method. This approach assesses gamma change by using the coefficient of congruence to compare factor structures of the Pre and Post measures. High positive coefficients indicate a lack of gamma change. Conversely, low positive coefficients indicate dissimilarity of factor structure (or gamma change), while negative coefficients indicate extremely different factor structures.

Since relatively independent, internally consistent, and conceptually meaningful scales were used here, an adaptation of the coefficient of congruence was used to assess gamma change. (Scale intercorrelations and alpha coefficients are available from the senior author.) Specifically, item-scale correlations for the Pre and Post measures were com- 
puted (corrected item-total correlations for the items belonging to a given scale). The Pre item-scale correlations were then correlated with the Post itemscale correlations for the control and the experimental groups. Note that this procedure is not the same as asking whether some common factor structure exists at both points in time. However, since both Pre and Post measures are being compared to a common a priori standard, comparisons against this standard yield information on change and seemed more reasonable than empirical factor analyses in this context.

Results. The resultant correlation matrices are presented in Table 1. While there is no comparable research with which to evaluate these correlations, some within-study comparative statements seem appropriate. First, the control group factor structure seems to have changed more than the experimental group, as evidenced by the lack of similarity of item-scale correlations across time. Second, if the diagonal correlations are compared with the offdiagonal correlations, it is clear that across-time items generally maintained their meaning relative to their a priori scales. One possible exception to the generally high across-time correlations in both experimental and control groups involves the Student Interest scale. In the experimental group, the correlations between the Student Interest item-scale correlations at Time 2 and the Course Demand item-scale correlations at Time 1 was greater than the Student Interest cross-time correlation. In the control group, the cross-time correlation for Stu- dent Interest was only .26 , and item-scale correlations of the Student Interest scale at Time 1 with the other two scales were greater than .26 , though one of these correlations was negative. The conclusion with respect to gamma change is that there may have been some minimal change involving the Student Interest scale, but there was relatively little evidence of differential change in the experimental and control groups.

The results of analyses designed to detect the five cases of alpha and/or beta change are presented in Table 2. Tests of significance (dependent $t$-tests) were used to answer the Yes-No questions suggested by Zmud and Armenakis (1978, p. 668), and the results indicated little alpha or beta change. In the only situation (Course Organization in the experimental group) in which the Time 1-Time 2 comparisons were significantly different, the pattern of differences did not represent a typical alpha or beta change. Rather, the direction of the mean differences seemed most like a No-No-No situation (the Zmud-Armenakis Case IV), indicating both alpha and beta change. However, the differences in means for Actual and Ideal measures were minimal and nonsignificant.

Summary. These analyses indicate that little gamma, beta, or alpha change occurred in either the control or experimental groups, though there was evidence of gamma change with respect to the Student Interest scale. Beyond the absence of change, it is also clear that when an attempt is made to operationalize these analyses, several judgments

Table 1

Gamma Change: Zmud and Armenakis Analyses

\begin{tabular}{|c|c|c|c|c|c|c|c|c|}
\hline & \multicolumn{4}{|c|}{ Experimental Group } & \multicolumn{4}{|c|}{ Control Group } \\
\hline & Inst1 & StInl & $\mathrm{CD1}$ & $\overline{\mathrm{COI}}$ & Inst1 & StIn1 & CD1 & $\mathrm{COI}$ \\
\hline Inst 2 & .65 & -.36 & .22 & -.12 & .44 & .13 & -.42 & -.60 \\
\hline St In 2 & .20 & .46 & .56 & .08 & $\overline{.12}$ & .26 & .10 & .08 \\
\hline $\mathrm{CD} 2$ & .14 & $\overline{.23}$ & .68 & .01 & -.48 & $-\overline{-34}$ & .33 & -.17 \\
\hline $\mathrm{CO} 2$ & .17 & -.22 & $\overline{.09}$ & .57 & -.12 & .36 & $-\overline{.01}$ & .68 \\
\hline
\end{tabular}

Note. Underlined correlations represent correlations associated with the same factor over time. 
Table 2

Alpha and Beta Change: Zmud and Armenakis Analyses

\begin{tabular}{|c|c|c|c|c|c|c|c|c|}
\hline & \multicolumn{4}{|c|}{ Control Group } & \multicolumn{4}{|c|}{ Experimental Group } \\
\hline & $\begin{array}{c}\text { Does } \\
\mathrm{D}_{1}=\mathrm{D}_{2} ?\end{array}$ & $\begin{array}{c}\text { Does } \\
\mathrm{A}_{1}=\mathrm{A}_{2} ?\end{array}$ & $\begin{array}{c}\text { Does } \\
I_{1}=I_{2} ?\end{array}$ & Change & $\begin{array}{c}\text { Does } \\
\mathrm{D}_{1}=\mathrm{D}_{2} ?\end{array}$ & $\begin{array}{c}\text { Does } \\
A_{1}=A_{2} ?\end{array}$ & $\begin{array}{c}\text { Does } \\
\mathrm{I}_{1}=\mathrm{I}_{2} ?\end{array}$ & Change \\
\hline \multicolumn{9}{|l|}{ Inst } \\
\hline Time 1 & -1.05 & 2.74 & 1.70 & & -1.13 & 2.78 & 1.65 & \\
\hline Time 2 & -1.07 & 2.67 & 1.61 & & -1.28 & 2.79 & 1.52 & \\
\hline t-value & .27 & 1.22 & 1.36 & & 1.53 & -.13 & 1.66 & \\
\hline Answer & Yes & Yes & Yes & None & Yes & Yes & Yes & None \\
\hline \multicolumn{9}{|l|}{ StIn } \\
\hline Time 1 & -.84 & 2.60 & 1.77 & & -.85 & 2.61 & 1.76 & \\
\hline Time 2 & -.91 & 2.68 & 1.77 & & -1.06 & 2.68 & 1.63 & \\
\hline t-value & .86 & -1.26 & .00 & & 1.07 & -.90 & 1.38 & \\
\hline Answer & Yes & Yes & Yes & None & Yes & Yes & Yes & None \\
\hline \multicolumn{9}{|l|}{$C D$} \\
\hline Time 1 & -.82 & 2.73 & 1.92 & & -.75 & 2.80 & 2.05 & \\
\hline Time 2 & -.74 & 2.73 & 1.99 & & -.87 & 2.85 & 1.98 & \\
\hline t-value & -.88 & .06 & -.85 & & 1.22 & -.54 & .87 & \\
\hline Answer & Yes & Yes & Yes & None & Yes & Yes & Yes & None \\
\hline \multicolumn{9}{|l|}{$\mathrm{CO}$} \\
\hline Time 1 & -.95 & 2.51 & 1.56 & & -.86 & 2.51 & 1.65 & \\
\hline Time 2 & -.87 & 2.48 & 1.61 & & -1.15 & 2.65 & 1.50 & \\
\hline t-value & -.63 & .37 & -.55 & & 2.49 & -1.51 & .53 & \\
\hline Answer & Yes & Yes & Yes & None & No & Yes & Yes & None \\
\hline
\end{tabular}

are required. Further, there is little or no background research with which to compare results and conclusions.

\section{Terborg-Howard-Maxwell Analyses}

Method. To assess gamma change, Terborg et al. (1980) suggested the analysis of both profile shapes and dispersions. First, they proposed computing correlations between each pair of Pre, Post, and Then profiles for each participant (i.e., each person would have three correlations: one for Pre/ Post, one for Pre/Then, and one for Post/Then). Next, the raw difference score between each pair of correlations is computed. If gamma change had occurred, $r_{\text {Pre/Post }}$ should be similar to $r_{\text {Pre/Then }}$, but $r_{\text {PostThen }}$ should be greater than the other two cor- relations. With no gamma change, all correlations should be similar. Mann-Whitney $U$ tests $(Z$ in Table 3 ) of group differences were computed three times for each student evaluation dimension: (1) for the ranked difference scores of $r_{\text {PostThen }}$ minus $r_{\text {Pre/Post }}$, (2) on the ranked difference scores of $r_{\mathrm{Pos} U T h e n}$ minus $r_{\mathrm{Pre} / \mathrm{Then}}$, and (3) on the ranked difference scores of $r_{\mathrm{Pre} / \mathrm{Post}}$ minus $r_{\mathrm{Pre} / \mathrm{Then}}$.

The second approach to assess gamma change using profile dispersions requires that for each individual, the raw difference scores between standard deviations for Pre, Post, and Then profiles be computed. If the scale is unidimensional at pretest but multidimensional at posttest, then the standard deviations of the Post and Then profiles should be larger than the standard deviation of the Pre profile. Three Mann-Whitney $U$ tests are done to compare the experimental and control groups. Gamma change 
in the experimental group but not in the control group would be indicated by a significant MannWhitney $U$ for Post-Pre and Pre-Then differences. That is, if gamma change has occurred, those in the experimental group should have large differences between Post-Pre and Pre-Then standard deviations relative to those in the control group.

Results. The results of analyses for both shape and dispersion are presented in Table 3 . The profile shape analyses indicated some gamma change in the experimental group; that is, $r_{\mathrm{Pre} / \mathrm{Post}}$ and $r_{\mathrm{PreThen}}$ correlations were similar, but the other two correlational differences were generally greater for the experimental than the control group. However, none of these differences was statistically significant. Analysis of the profile dispersion data indicated that Post standard deviations were larger than Pre or Then standard deviations for both groups, so it is possible that persons in both groups experienced some small amount of gamma change.
For individuals in both groups, alpha change was assessed by first computing the $t$-values representing the difference between Post and Then measures. The Mann-Whitney test for ranked differences was again used to compare the control and experimental groups. A similar procedure was used to identify beta change except that the $t$-values were computed from responses to Pre and Then measures. The results of alpha and beta change analyses are presented in Table 4. Negative values indicated change from a positive to a negative evaluation of the faculty member, and positive values indicated a more favorable response to the instructor at the second data collection. In most cases, a negative change in student evaluation occurred. Significant alpha change occurred for Student Interest and Course Organization, and beta change occurred for Student Interest. The control group experienced more negative change than did the experimental group.

Table 3

Garma Change: Terborg, Howard, and Maxwell Analyses

\begin{tabular}{|c|c|c|c|c|c|c|c|c|c|}
\hline & \multicolumn{9}{|c|}{ Profile Shape } \\
\hline & \multicolumn{3}{|c|}{$\begin{array}{l}\mathrm{r}_{\text {pre/post }} \\
\quad-\mathrm{r} \text { pre/then } \\
\end{array}$} & \multicolumn{3}{|c|}{$\begin{array}{l}r_{\text {post } / \text { then }} \\
-r_{\text {pre/post }}\end{array}$} & \multicolumn{3}{|c|}{$\begin{array}{l}r_{\text {post } / \text { then }} \\
-r_{\text {pre } / \text { then }}\end{array}$} \\
\hline & $\overline{\mathrm{X}} \mathrm{c}$ & $\overline{\mathrm{X}} \mathrm{e}$ & $\mathrm{z}$ & $\overline{\mathrm{X}} \mathrm{c}$ & $\overline{\mathrm{X}} \mathrm{e}$ & $\mathrm{z}$ & $\overline{\mathrm{X}}_{\mathrm{c}}$ & $\overline{\mathrm{X}} \mathrm{e}$ & $z$ \\
\hline $\begin{array}{l}\text { Inst } \\
\text { StIn } \\
C D \\
C O\end{array}$ & $\begin{array}{r}-.041 \\
-.128 \\
-.032 \\
.058\end{array}$ & $\begin{array}{r}.005 \\
-.0152 \\
-.019 \\
-.017\end{array}$ & $\begin{array}{r}-.61 \\
.04 \\
-.84 \\
.53\end{array}$ & $\begin{array}{r}.007 \\
.078 \\
-.004 \\
.032\end{array}$ & $\begin{array}{l}.008 \\
.134 \\
.135 \\
.263\end{array}$ & $\begin{array}{l}-1.11 \\
-1.25 \\
-1.35 \\
-1.69\end{array}$ & $\begin{array}{r}-.034 \\
-.050 \\
-.036 \\
.089\end{array}$ & $\begin{array}{r}.093 \\
-.018 \\
.116 \\
.246\end{array}$ & $\begin{array}{r}-1.28 \\
-.14 \\
-.93 \\
-1.11\end{array}$ \\
\hline \multirow{3}{*}{$\mathrm{CO}$} & \multicolumn{9}{|c|}{ Profile Dispersions } \\
\hline & \multicolumn{3}{|c|}{$\mathrm{SD}_{\text {post }}{ }^{-S D_{\text {then }}}$} & \multicolumn{3}{|c|}{${ }_{\text {post }}{ }^{-S D}$ pre } & \multicolumn{3}{|c|}{$\mathrm{SD}_{\text {pre }}{ }^{-S D_{\text {then }}}$} \\
\hline & $\overline{\mathrm{X}}_{\mathrm{c}}$ & $\overline{\mathrm{X}} \mathrm{e}$ & $z$ & $\overline{\mathrm{X}}_{\mathrm{c}}$ & $\overline{\mathrm{X}} \mathrm{e}$ & $\mathrm{Z}$ & $\overline{\mathrm{X}}_{\mathrm{c}}$ & $\overline{\mathrm{X}} \mathrm{e}$ & $\mathrm{z}$ \\
\hline $\begin{array}{l}\text { Inst } \\
\text { St In } \\
\text { CD } \\
\text { CO }\end{array}$ & $\begin{array}{l}.36 \\
.39 \\
.38 \\
.06\end{array}$ & $\begin{array}{r}.46 \\
.27 \\
.42 \\
-.04\end{array}$ & $\begin{array}{r}-1.35 \\
1.10 \\
-.64 \\
1.55\end{array}$ & $\begin{array}{r}.33 \\
.34 \\
.33 \\
-.01\end{array}$ & $\begin{array}{r}.31 \\
.31 \\
.39 \\
-.01\end{array}$ & $\begin{array}{r}.08 \\
.37 \\
-.73 \\
-.37\end{array}$ & $\begin{array}{l}-.04 \\
-.06 \\
-.06 \\
-.07\end{array}$ & $\begin{array}{r}-.15 \\
.04 \\
-.04 \\
.02\end{array}$ & $\begin{array}{r}1.92 \\
-.44 \\
-.51 \\
-1.24\end{array}$ \\
\hline
\end{tabular}

Note. $\overline{\mathrm{X}} \mathrm{c}$ and $\overline{\mathrm{X}} \mathrm{e}$ refer to the means of the control and experimental groups, respectively. $Z$ refers to the test of significance of the difference of the ranks in the two groups. None of the $Z^{\prime}$ 's in this table are statistically significant. 
Table 4

Alpha and Beta Change: Terborg, Howard, and Maxwell Analyses

\begin{tabular}{|c|c|c|c|c|c|c|}
\hline & \multicolumn{3}{|c|}{ Alpha Change } & \multicolumn{3}{|c|}{ Beta Change } \\
\hline & $\overline{\mathrm{X}}_{\mathrm{c}}$ & $\overline{\mathrm{X}} \mathbf{e}$ & $z$ & $\overline{\mathrm{X}}_{\mathrm{c}}$ & $\overline{\mathrm{X}} \mathrm{e}$ & $\mathrm{z}$ \\
\hline Inst & -.209 & -.179 & .07 & -.139 & -.189 & .69 \\
\hline StIn & -.230 & -.066 & $-2.13 *$ & -.307 & -.143 & $-2.00 *$ \\
\hline $\mathrm{CD}$ & -.078 & .026 & -1.26 & -.074 & -.026 & -.62 \\
\hline $\mathrm{CO}$ & -.193 & .015 & $-2.43^{\star}$ & -.160 & -.130 & -.44 \\
\hline
\end{tabular}

Note. ${ }^{t_{\mathrm{p}}}<.05 . \quad \overline{\mathrm{X}} \mathrm{c}$ and $\overline{\mathrm{X}} \mathrm{e}$ refer to the means of the control and experimental groups, respectively. Differences were calculated by subtracting Then scores from Post and Pre scores for alpha and beta change, respectively. $Z$ refers to the test of significance of the difference of ranks in the two groups.

Another approach for assessing alpha and beta change tested actual mean differences in Pre, Post and Then scores for the experimental and control groups. A 2 (experimental vs. control) $\times 3$ (Pre, Post, Then) ANOVA with repeated measures on the second factor was performed for each of the four dimensions. These analyses (see Table 5) revealed no significant effects for Group or for the Group $\times$ Measure interaction. However, there was a significant Measure effect for three of the dependent measures. This was primarily because the Then measures were higher than the Pre or Post measures. Perceptions of the course at the beginning of the term, as assessed by the Then measure, were somewhat better than perceptions at the time of the first exam and at the time of the first data collection, but there was no difference between those who had experienced the first exam and those who had not.

Summary. There was no evidence of between group differences in gamma change, although the pattern of correlations between the Pre, Post, and Then profiles and the standard deviations suggested some gamma change in both groups. Significantly greater beta change resulted in the control group than in the experimental group on Student Interest. Significant alpha change was observed for Student Interest and Course Organization.

\section{Schmitt Analyses}

Method. This approach posits the following model for each set of measurements (before-after or over three or more sets of measurements):

$\mathbf{X}=\boldsymbol{\Lambda} f+u$

where $\mathbf{X}$ is the vector of observed responses,

$f$ is (are) the common factor loadings,

$u$ is (are) the unique factor(s), and

$\boldsymbol{\Lambda}$ is the set of factor loadings.

The expected variance-covariance matrix, $\mathbf{\Sigma}$, of $\mathbf{X}$ is $\boldsymbol{\Lambda} \boldsymbol{\phi} \boldsymbol{\Lambda}+\boldsymbol{\delta}$ where $\boldsymbol{\phi}$ is the variance-covariance matrix of the common factors and $\boldsymbol{\delta}$ is the diagonal matrix of the variances of the unique factors. The elements in $\boldsymbol{\Lambda}, \boldsymbol{\phi}$, and $\boldsymbol{\delta}$ can be fixed at some value such as 0 or 1 , constrained to be equal with other parameters, or free. LISREL (Jöreskog \& Sörbom, 1981) was the computer program used to estimate these parameters. The analysis to assess gamma and beta change proceeded in five steps. Assessment of alpha change involves the relatively uncomplicated test of mean change and is not included here, though LISREL and similar techniques are available to test differences in factor means and structure simultaneously (Jöreskog \& Sörbom, 1981; Sörbom, 1974; Sörbom \& Jöreskog, 1976).

The first step (Model 1) was to test the hypothesis that the Pre and Post variance-covariance matrices 
Table 5

Analysis of Variance of Student

Evaluations and Cell Means

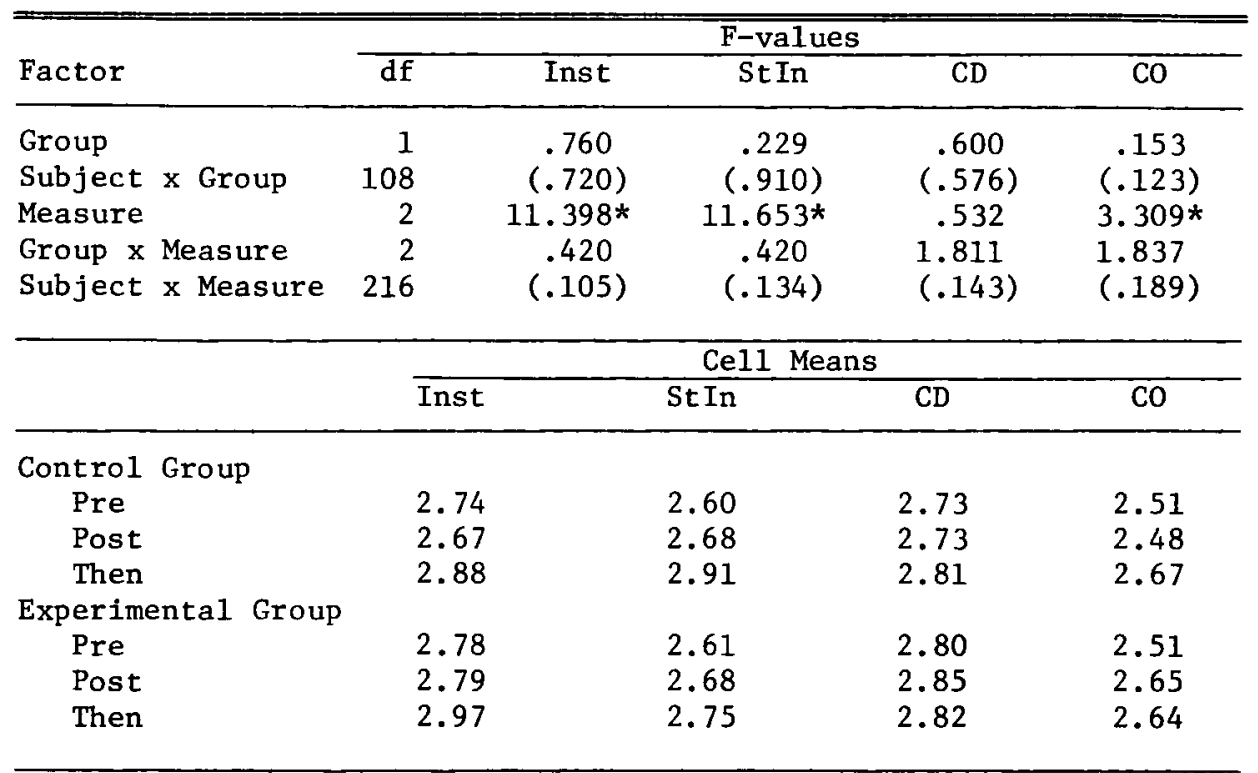

Note. ${ }^{\star} \mathrm{p}<.05$. Numbers in parentheses are mean square errors associated with the F-values immediately above them in the table.

are equal. A significant difference in the matrices implies either (1) the factor pattern is different, that is, some unspecified gamma change has occurred, (2) the scale units are different, that is, some unspecified beta change has occurred, (3) the uniquenesses are different, or (4) some combination of these three has occurred.

Second, in Model 2 assessment was made of the extent to which the Pre-Post measurements were measuring the same concepts. If the same factors are being measured, then the number of factors and the pattern of factor loadings will be the same. At this stage, neither the factor loadings nor the uniquenesses are constrained to be equal across time. In both the before and after matrices, the first element of each factor is arbitrarily fixed at 1.0 to scale the factors in terms of the $x$ observed units. The content of the present instrument suggested 4 common and 16 unique factors. If this model is correct, then the difference between the observed variance-covariance matrix and the expected ma- trix produced by the parameters indicated by the model would be a null matrix. That is, all elements in the observed matrix would be perfectly reproduced by the parameters in the model. Also, the $\chi^{2}$ testing the difference between the observed and reproduced matrices would be nonsignificant (see Jöreskog, 1969, for a description of this test).

For the data described above, each observed variable is hypothesized to result from a single construct, from the interrelationship of that construct with other constructs, and from a uniqueness element via Equation 1. While the same pattern is used to explain the data at both Pre and Post examination, different factor loadings, variances, and interrelationships are estimated for data collected at Times 1 and 2 .

The possibility of gamma change was further tested (Model 3) by fixing the corresponding elements of the variance-covariance matrix to be equal. In effect, positing no gamma change means the relationship among the four student evaluation fac- 
tors should be the same before and after the examination. By constraining these parameters to be equal, 10 fewer parameters are estimated, which results in a gain of 10 degrees of freedom. The difference between the observed variance-covariance matrix and that reproduced by the model would be larger by some amount that would represent gamma change. The difference of the $\chi^{2}$ s associated with these two models is distributed approximately as a $\chi^{2}$ with degrees of freedom equal to the difference in degrees of freedom associated with the two models (i.e., 10 in this case). Hence, the implications of restricting the factor covariances to be equal can be evaluated by means of a statistical test.

The fourth hypothesis investigated in Model 4 was that the factor loadings (elements of $\Lambda$ ) were equal across time. Since the $\Lambda$ s are the maximum likelihood estimates of the regressions of the observed scores on true scores (provided there is proper specification of the dimensionality), the constraint of equality across time is a test of the equality of the scaling units or the existence of beta change. It should be noted, however, that individual items within a scale are not assumed to have equal scale units across time. The test concerns the equality of scaling units in the factors; hence, multiitem measurement of constructs is essential.

Thus, a four-factor model was evaluated in which loadings for the Pre-Post measure are set equal, and only one value was used to represent the Pre and Post factor loadings. Setting them equal gains 12 degrees of freedom. When beta change occurs, there should be a significant drop in fit between the observed and reproduced matrices. As above, the significance of that loss of fit can be tested using the differences in $\chi^{2} s$ that result when factor loadings are restricted as opposed to the case in which two sets of loadings are estimated.

Model 5 involved an equality constraint on similar Pre-Post elements of $\boldsymbol{\delta}$, which are the uniquenesses associated with each measured variable. Since 16 observed variables were used, this restriction gains 16 degrees of freedom. Again, a significant $\chi^{2}$ or a significant decrease in the variance accounted for by the models signals a difference with respect to the reliability of measurement before and after intervention.

The $\chi^{2}$ measure is sensitive to sample size and departures from multivariate normality of the observed variables. Larger sample sizes and departures from normality inflate $\chi^{2}$ relative to what can be expected due to specification error in the model. Beyond the $\chi^{2}$ tests, the current version of LISREL provides two goodness-of-fit indices. The first is the goodness-of-fit index (GFI), which is a measure of the relative amount of variances and covariances accounted for by the model. While GFI's statistical distribution is unknown, its limits are zero and one. The second index, the root mean square residual (RMR), is a measure of the average of the residual variances and covariances. The RMR must be interpreted in relation to the sizes of the variances and covariances in the observed variance-covariance matrix. Both RMR and GFI are useful in comparing the fit of different models; GFI is also useful for comparing the fit of models to different data.

Results. The results of the LISREL analyses for both experimental and control groups are presented in Table 6 . The test of the similarity of the Pre and Post matrices yielded a nonsignificant $\chi^{2}$ for the control group but a significant $\chi^{2}$ for the experimental group. Following the hypothesis testing procedure outlined above, the conclusion would be that there was no beta or gamma change for the control group. However, evaluation of subsequent models was undertaken to parallel those of the experimental group and because GFI was relatively low. Beyond the first comparison (Model 1-2) for the control group, the biggest change in GFI for both groups came when the factor loadings were restricted (comparing Models 3 and 4), indicating that beta change had occurred. This conclusion is further supported by the $\chi^{2}$ difference test for both experimental and control groups. The GFI and the $\chi^{2}$ difference test also indicated that gamma change had occurred in the control group. The GFI, RMR, and $\chi^{2}$ difference test indicated little or no difference in Pre-Post uniquenesses.

The results presented in Table 6 are applicable only to the matrices as a whole, whereas the Ter- 
Table 6

Beta and Gamma Change: Schmitt Analyses

\begin{tabular}{|c|c|c|c|c|c|c|c|}
\hline \multirow[b]{2}{*}{ Mode1 } & \multirow[b]{2}{*}{ df } & \multicolumn{3}{|c|}{ Experimental Group } & \multicolumn{3}{|c|}{ Control Group } \\
\hline & & $x^{2}$ & GFI & RMR & $x^{2}$ & $\overline{\mathrm{GFI}}$ & RMR \\
\hline 1 & 136 & $212.09 *$ & .622 & .078 & 154.50 & .576 & .066 \\
\hline 2 & 196 & $317.27 *$ & .638 & .078 & $273.11 *$ & .741 & .041 \\
\hline 3 & 206 & $329.70 *$ & .613 & .094 & $333.04 *$ & .703 & .056 \\
\hline 4 & 218 & $363.69 *$ & .532 & .122 & $355.95 *$ & .634 & .066 \\
\hline 5 & 234 & $388.15 *$ & .514 & .125 & $369.72 *$ & .629 & .068 \\
\hline \multirow{2}{*}{\multicolumn{3}{|c|}{ Difference }} & \multirow[b]{2}{*}{$\mathrm{df}$} & \multicolumn{4}{|c|}{ Cel1 Means } \\
\hline & & & & \multicolumn{2}{|c|}{ Experimental Group } & \multicolumn{2}{|c|}{ Control Group } \\
\hline \multirow{3}{*}{$\begin{array}{l}3-2 \\
4-3 \\
5-4\end{array}$} & \multirow{3}{*}{\multicolumn{2}{|c|}{$\begin{array}{l}\text { (Gamma) } \\
\text { (Beta) } \\
\text { Uniquenesses) }\end{array}$}} & 10 & \multicolumn{2}{|c|}{12.43} & \multicolumn{2}{|c|}{$59.93 *$} \\
\hline & & & 12 & \multicolumn{2}{|c|}{$33.99 *$} & \multicolumn{2}{|c|}{$22.91 *$} \\
\hline & & & 16 & \multicolumn{2}{|c|}{24.46} & \multicolumn{2}{|c|}{13.77} \\
\hline
\end{tabular}

${ }^{\star} \mathrm{p}<.05$

borg et al. (1980) analysis and the Zmud and Armenakis (1978) analysis provided detail concerning change along all four student evaluation dimensions. LISREL can be adapted to test for individual factors as well. For example, separate parameters for the factor loadings for Instructor Involvement items could be estimated for Pre and Post matrices, while the remaining factor loadings could be constrained to be equal across time. This model compared with a model in which all factor loadings were constrained would constitute a test of beta change for Instructor Involvement only. Similar portions of the $\boldsymbol{\phi}$ matrix (relationships among the common factors) could be constrained to test for gamma change along individual dimensions.

Summary. The LISREL analyses indicated that beta change had occurred in the experimental group. Both gamma and beta change were observed in the control group; however, the tests for these two types of change were preceded by the finding of a nonsignificant difference between the Pre and Post covariance matrices.

\section{Comparison of Analyses}

This paper compared the results of three analytical techniques that purport to assess the existence of alpha, beta, and gamma change, the latter two being of most interest. On an absolute level, there seems to be more agreement between the Terborg et al. (1980) and Schmitt (1982) analyses. The beta change identified by the Terborg et al. approach is reflected in the Schmitt results. The Schmitt approach identified relatively strong gamma change in the control group but not in the experimental group. The Terborg et al. analysis did not indicate differential gamma change, but there certainly were changes in standard deviations.

The Zmud and Armenakis results are most in conflict with the results from the other two approaches for beta change. While Zmud and Armenakis (1978) did not propose the use of $t$-tests to compare actual, ideal, and difference scores, Table 3 indicates that the pattern and magnitude of change was inconsistent with any of their five cases of alpha and beta change. The coefficient of congruence computed here to assess gamma change indicated that gamma change was more likely in the control group but possible in both groups. The Zmud and Armenakis evaluation of gamma change, then, was most consistent with the Schmitt analysis, which also found evidence of gamma change in the control group.

\section{Additional Considerations and Conclusions}

The assessment of alpha, beta, and gamma change by any one of these techniques is extremely com- 
plex. All three procedures incorporate tests of significance; but, the power of these tests, the use of multiple tests of significance, and the fact that there is little published research using the techniques make conclusions regarding change, or lack thereof, problematic. In addition, questions concerning the practical significance of any of these changes remain unexplored.

At this point, the use of either or both the Terborg et al. (1980) analysis or the LISREL approach is recommended. There are two reasons for not recommending the Zmud and Armenakis (1978) analysis. First, the present results indicate that the procedure leads to different conclusions concerning beta change than the other two approaches. Second, and perhaps more important, is the almost inevitable existence of a ceiling effect for ideal measures. As is evident in Table 2, most of the student responses indicated that the ideal state was the endpoint of the scale (1.0). This, of course, makes change in the ideal measure impossible and any observation of a response shift potentially artifactual (see Terborg et al., 1980 for a similar discussion).

The other two techniques are not without problems. While Terborg et al. (1980) use means, standard deviations, correlations, and $t$-tests, which are familiar to behavioral science researchers, their use of these statistics is unconventional, and the effects of such use are unknown. Further, this approach requires collecting large amounts of data from potentially disgruntled respondents. There is also the necessity to have scales with a relatively large number of items. Computation of correlations among Pre, Post, and Then profiles or computation of standard deviations for four items, as was done here, are certainly marginal. A second, relatively minor point relates to the procedure as outlined by Terborg et al. (1980) and used to produce Tables 3 and 4 in this study. That is, the approach focuses on differences between a control group and an intervention group but does not test whether or not both groups may have changed, as appears to be true for the present data. A more complete way to look at the results seems to be by means of the ANOVA (Table 5) followed by post hoc comparisons of individual measure differences. In fact,
Terborg and Davis (1982) used a similar approach. Finally, while not used in this study, the Terborg et al. method is the only one that allows the assessment of individual change. This may be of great practical importance if a researcher is interested in identifying what type of individual does or does not change as a result of some intervention.

LISREL shares some disadvantages of the other two methods in terms of what constitutes meaningful change. It also involves the use of an analytical procedure that may be unfamiliar to many researchers. Another problem that can and often does occur is that data do not fit the models specified, resulting in an inability to estimate parameters in one or more matrices $(\phi, \Lambda$, or $\delta$ in this case). Further, it is difficult to assess the practical significance of a significance test. A good example is the control group analysis reported here. While the initial analysis indicated no significant difference between Pre and Post covariance matrices, the GFI and subsequent analyses indicated some beta and gamma change had probably occurred. Finally, it is unknown how the scale changes that mimic beta change affect the multivariate normality assumptions of the various significance tests involved in the covariance analyses. However, the logic of hypothesis testing and the lack of necessity to collect additional forms of the measures make LISREL an appealing alternative.

The present data were not ideal in that it might be preferable to have greater change and larger differences between experimental and control groups when comparing analytical techniques. Also, it is not known whether beta or gamma change should have been found in the present study. Perhaps no change occurred and evidence that it did was artifactual. One obvious way to deal with this possibility would be to conduct research in which beta or gamma change are clearly hypothesized as a result of some intervention. A second potentially promising approach was illustrated by Schmitt (1982) who transformed a set of data in ways suggested by conceptual definitions of beta and gamma change and then assessed whether these changes were correctly identified by LISREL analyses. Similar transformations and monte carlo studies comparing the three analytical techniques used here may be 
particularly useful. Varying the degree. and type of transformation would also allow some estimate of the practical importance of beta and gamma change.

This leads to the final conclusion; namely, that much more comparative work is essential. A call for more research is traditional and a bit disconcerting; but, it seems that much more data must be presented before researchers can interpret meaningful beta and gamma changes using any of the methods discussed here. Such research should definitely be encouraged, since many training programs and organizational change efforts imply beta and gamma rather than alpha change.

\section{References}

Ahmavaara, Y. (1954). Transformation analysis of factorial data. Annales Academiae Scientarium Fennical, 881 (Series B), 54-59.

Cronbach, L. J., \& Furby, L. (1970). How should we measure change-or should we? Psychological Bulletin, 74, 68-80.

Golembiewski, R. T., \& Billingsley, K. R. (1980). Measuring change in OD designs: A response to my critics. Academy of Management Review, 5, 97-103.

Golembiewski, R. T., Billingsley, K., \& Yeager, S. (1976). Measuring change and persistence in human affairs: Types of change generated by OD designs. Journal of Applied Behavioral Science, 12, 133-157.

Guilford, J. P. (1954). Psychometric methods. New York: McGraw-Hill.

Howard, G. S., \& Dailey, P. R. (1979). Response-shift bias: A source of contamination of self-report measures. Journal of Applied Psychology, 64, 144-150.

Howard, G. S., Schmeck, R. R., \& Bray, J. H. (1979). Internal validity in studies employing self-report instruments: A suggested remedy. Journal of Educational Measurement, 16, 129-136.

Jöreskog, K. G. (1969). A general approach to confirmatory maximum likelihood factor analysis. Psychometrika, 34, 183-202.
Jöreskog, K. G., \& Sörbom, D. (1981). LISREL V. Analysis of linear structural relationships by maximum likelihood and least squares methods. Uppsala, Sweden: University of Uppsala, Department of Statistics.

Rogosa, D., Brandt, D., \& Zimowski, M. (1982). A growth curve approach to the measurement of change. Psychological Bulletin, 92, 726-748.

Schmitt, N. (1982). The use of analysis of covariance structures to assess beta and gamma change. Multivariate Behavioral Research, 17, 343-358.

Sörbom, D. (1974). A general method for studying differences in factor means and factor structure between groups. British Journal of Mathematical and Statistical Psychology, 27, 229-239.

Sörbom, D., \& Jöreskog, K. G. (1976). COFAMM: Confirmatory factor analysis with model modification. User's guide. Chicago: National Educational Resources.

Terborg, J. R., \& Davis, G. A. (1982). Evaluation of a new method for assessing change in planned job redesign as applied to Hackman and Oldham's job characteristics model. Organizational Behavior and Human Performance, 29, 112-128.

Terborg, J. R., Howard, G. S., \& Maxwell, S. E. (1980). Evaluating planned organizational change: A method for assessing alpha, beta and gamma change. Academy of Management Review, 5, 109-121.

Werts, C. E., Rock, D. A., Linn, R. L., \& Jöreskog, K. G. (1977). Validating psychometric assumptions within and between populations. Educational and Psychological Measurement, 37, 863-871.

Zmud, R. W. , \& Armenakis, A. A. (1978). Understanding the measurement of change. Academy of Management Review, 3, 661-669.

\section{Acknowledgment}

The authors thank Ronni Meritt for reading an earlier draft of this paper.

\section{Author's Address}

Send requests for reprints or further information to Neal Schmitt, Department of Psychology, Michigan State University, East Lansing MI 48824, U.S.A. 